\title{
Design and Synthesis of New Functional Materials Using the Interstices of Inorganic Host Structure
}

\author{
Shoji YAMANAKA \\ Department of Applied Chemistry, Graduate School of Engineering, Hiroshima University, \\ 1-4-1, Kagamiyama, Higashi-Hiroshima-shi 739-8527 \\ ナノ物質空間を利用する機能性材料の開発 \\ 山中昭司 \\ 広島大学大学院工学研究科, 739-8527 東広島市鏡山 1-4-1
}

\begin{abstract}
Effective use of the interstices of inorganic host structures is the key to develop new functional materials. The interstices in layer structured crystals are most versatile; the reaction concerning the interlayer space is called intercalation. Some examples of new functional materials developed using interstices are briefly reviewed, such as clay-organic complexes, porous pillared materials, interlayer grafting, anion exchangeable compounds, and layer structured nitride superconductors. A new silicon clathrate superconductor with a Si-sp ${ }^{3}$ cage structure is also introduced.

[Received May 27, 2004]
\end{abstract}

Key-words : Interstices, Intercalation, Layer structure, Porous crystals, Pillared materials, Clays, Anion exchange, Zirconium phosphate, Layer structured nitride, Electron-doping, Silicon clathrates, Superconductors, High pressure synthesis

\section{Introduction}

$\mathbf{I}^{\mathrm{N}}$ $\mathrm{N}$ the development of new functional materials, usually much attention has been paid to atoms, ions, molecules, and chemical bonds. Attention should also be paid to interstices of materials left unoccupied by these chemical species. A good and successful example is the development of electrodes for lithium ion batteries, which are widely used in recent portable electric equipments. The interstices formed by close-packed oxygen ions in $\mathrm{Li}_{x} \mathrm{CoO}_{2}$ play a key role in the cathode; the deintercalation-intercalation behavior of lithium ions from and into these interstices determine the performance of the batteries. The anode also uses specially designed nano-interstices of graphite layers. Ceramic porous materials having interstices for adsorption of various molecules are key materials to solve environmental issues. Pores are classified into three types depending on the pore diameter $(d)$; micropores with $d<2 \mathrm{~nm}$, mesopores with $d \sim 2-50 \mathrm{~nm}$, and macropores with $d>\sim 50 \mathrm{~nm}$. Microporous ceramic materials which are able to recognize and adsorb specific molecules are useful for adsorbents, catalysts, and catalytic supports.

The property of inorganic host structure having accessible interstices can be easily modified without changing the basic structure. Electric carriers such as electrons and holes can be doped into inorganic host structures through the interstices, and the electric properties are drastically altered. It is frequently found that electric insulators are changed into metals and superconductors by such doping. A variety of interesting intercalation compounds have been reported for transition metal chalcogenides, graphite, and transition metal oxides.

In this paper, some new functional materials developed in our research group using interstices of inorganic host structure are briefly reviewed.

\section{Intercalation}

Layer structured crystals are the most versatile inorganic hosts. The reaction concerning with the interlayer space is called intercalation. In layer structured crystals, the chemical bonds within the two-dimensional layers are relatively strong, whereas the interlayer interaction is mainly due to van der Waals, or weak ionic force, and thus various guest species can be intercalated between the layers. Although the number of such layer structured crystals which can form intercalation compounds is not so large, layer structured crystals have a freedom along the direction perpendicular to the layers; the basal spacing can expand, adjusting to the size of the intercalated molecules, and can accommodate a variety of guest molecules and ions. Therefore the number of combinations is actually infinite.

There are two types of layer structured crystals as schematically shown in Fig. 1;

(a) Molecular layer structured crystals

(b) Ion-exchangeable layer structured crystals In molecular type such as graphite and transition metal dichalcogenides, the composed layers are neutral, and are stacked each other by a weak van der Waals interaction or hydrogen bonds. In ion-exchangeable type, the layers are charged, and oppositely charged ions rest in the interlayer space, which are often ion-exchangeable. The intercalation mechanisms vary by

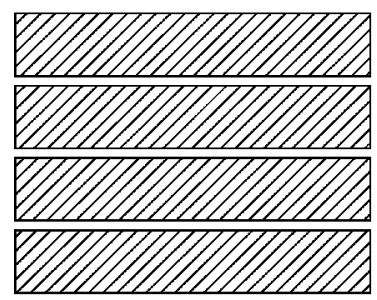

(a)

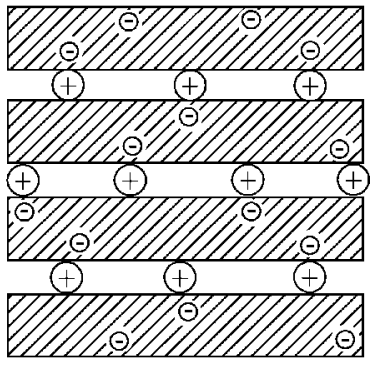

(b)
Fig. 1. Schematic drawing of two types of layer structured hosts; (a) molecular and (b) ion-exchangeable layer structured crystals. 
the type of host structures. ${ }^{1)}$ The intercalation in molecular crystals occurs by redox reaction with guest species, while in ion-exchangeable crystals the interlayer ions are exchanged with foreign ions or the ions between the layers are coordinated with polar solvent molecules by ion-dipole interaction. The reactivity of the ion-exchangeable layers depends on the ionexchange capacity of the layers. The exchangeable ions are usually cations; anion exchangeable layers are very rare as will be described later. If the cation exchange capacity (CEC) is too large, the electrostatic interaction between the exchangeable cations and the negatively charge layers are too strong for molecules to co-intercalate by expanding the interlayer space. On the other hand, if the charge density is too small, the driving force for intercalation, ion-dipole interaction, is totally too small to gain the solvation energy. Note that the interstices of molecular type layer structured crystals cannot be used by most of neutral molecules, since the layers have no cations to be coordinated.

\section{Clay organic complexes}

A naturally occurring clay mineral, montmorillonite, is the most popular and useful ion-exchangeable host structure for intercalation. It is a layer structured silicate composed of two silica-tetrahedral sheets and one gibbsite $\mathrm{Al}(\mathrm{OH})_{3}$ octahedral sheet coupled to form 2:1 silicate layers. The $\mathrm{Al}^{3+}$ of the octahedral sheet is partially substituted with lower valent cations such as $\mathrm{Mg}^{2+}$ and $\mathrm{Fe}^{2+}$, and the layer is negatively charged. This net charge is balanced by the positive charge of cations such as $\mathrm{Na}^{+}, \mathrm{K}^{+}$, and $\mathrm{Ca}^{2+}$ located between the layers. The CEC of motmorillonite $(\sim 80 \mathrm{meq} / 100 \mathrm{~g})$ is not too large nor too small, just favorable to intercalate polar molecules by cation-dipole interactions. It is also suitable for intercalation by cation-exchange with foreign cations such as large alkylammonium ions.

The mechanism of the intercalation of neutral molecules was studied using the adsorption of acrylonitrile (AN) into variously ion-exchanged montmorillonites. ${ }^{2), 3)}$ The infrared study showed that the $\mathrm{CN}$ group of $\mathrm{AN}$ was bound to the interlayer cations, and the strength of the interaction increased with the increase of the polarizing power of the cations, $Z / r$ where $Z$ is the formal charge of the cations and $r$ is the cation radius.

The most remarkable and industrially useful property of montmorillonite is osmotic swelling; the silicate layers swell in water infinitely. However, montmorillonite shows only a limited swelling (crystalline swelling) in sea water, which restricts the application field of montmorillonite. ${ }^{4)}$ Recently, Onikata et al..$^{5,6)}$ found that montmorillonite complexed with propylene carbonate (PC) exhibited osmotic swelling even in sea water. The swelling in sea water has been explained in terms of the larger donor number of water than that of PC and bi-functionality of water molecules, in coupled with the polarizing power of the cations.

\section{Organic derivatives of inorganic layers}

The interlayer surface of most of layered crystals consists of closely packed atom layers. Generally, it is very difficult to graft organic functional groups onto such surface. Among a number of layered crystals, zirconium phosphate is very special from a structural view point that the interlayer surface has reactive functional groups directing outside the layers; the tips of phosphate groups are directing toward the adjacent layers, which can be modified by organic functional groups through ester bonds. ${ }^{7)}$

There are two layer structured polymorphs for zirco- nium phosphates; $\alpha$-form, $\mathrm{Zr}\left(\mathrm{HPO}_{4}\right)_{2} \cdot \mathrm{H}_{2} \mathrm{O}$ and $\gamma$-form, $\mathrm{Zr}\left(\mathrm{H}_{2} \mathrm{PO}_{4}\right)\left(\mathrm{PO}_{4}\right) \cdot 2 \mathrm{H}_{2} \mathrm{O}$. The $\gamma$-form is a more reactive intercalation host. ${ }^{7)}$ Although the $\gamma$-form had long been considered to be something like polytype of the $\alpha$-form and had a formula $\mathrm{Zr}\left(\mathrm{HPO}_{4}\right)_{2} \cdot 2 \mathrm{H}_{2} \mathrm{O},{ }^{8)}$ recent ${ }^{31} \mathrm{P} \mathrm{NMR}$ study revealed that the two structures differ considerably. ${ }^{9}{ }^{9}$ The $\mathrm{H}_{2} \mathrm{PO}_{4}$ groups are situated on the interlayer surface and subjected to reaction with ethylene oxide (EO) to form ester bonds. ${ }^{10)}$ The basal spacing expanded from 1.23 to $1.6-2.0$ $\mathrm{nm}$, depending on the amount of EO reacted.

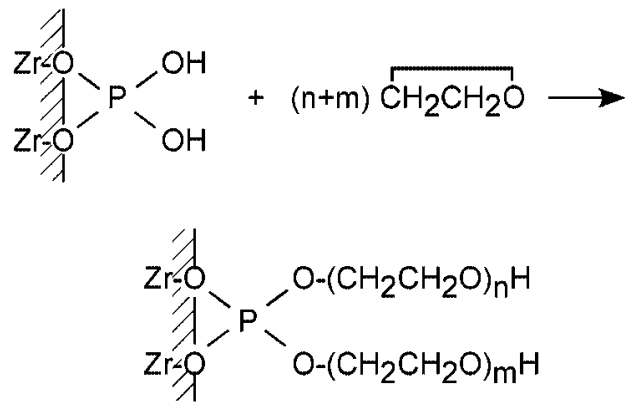

${ }^{31} \mathrm{P}$ cross-polarization (CP) MAS-NMR spectra were measured on the samples of different degrees of the reaction. ${ }^{11}$ Two sharp ${ }^{31} \mathrm{P}$ resonance peaks were clearly observed in the spectrum of the starting $\gamma$-zirconium phosphate at -8.90 and $-26.83 \mathrm{ppm}$, which were, respectively, assigned to $\mathrm{H}_{2} \mathrm{PO}_{4}$ and $\mathrm{PO}_{4}$ by Clayden. ${ }^{9}$ ) As the reaction with ethylene oxide proceeded, the intensity of the former peak due to $\mathrm{H}_{2} \mathrm{PO}_{4}$ was reduced and a new peak appeared at $13.24 \mathrm{ppm}$; the peak due to $\mathrm{PO}_{4}$ remained unshifted at $-26.9 \mathrm{ppm}$. This finding suggests that only half of the phosphate groups are used for the grafting reaction, though about two moles of ethylene oxide reacted with one mole of $\gamma$-zirconium phosphate. This was the first organic grafted derivative of inorganic interlayer surfaces. Similar organic derivatives of $\gamma$-zirconium phosphate were prepared by a direct exchange of the surface phosphate groups with phosphate esters or phosphonic acids. ${ }^{12)-18)}$

\section{Pillared materials}

Two-dimensional crystalline layers are used as building units to construct porous pillared structures. Smectite clays are the most useful host layers for pillaring. ${ }^{19), 20)}$ General procedures for the preparation of pillared clays are schematically illustrated in Fig. 2. The first and most important reaction for the introduction of pillars is ion-exchange; the hydrated interlayer cations of montmorillonite are exchanged with precursory polynuclear metal hydroxy cations such as $\left[\mathrm{Al}_{13} \mathrm{O}_{4}(\mathrm{OH})_{24}\right]^{7+}$ and $\left[\mathrm{Zr}_{4}(\mathrm{OH})_{14}\right]^{2+} .{ }^{21)}$ After the ion-exchange, the montmorillonite is separated by centrifugation and washed with water to remove excess metal hydroxy ions. The interlayered metal hydroxy cations are then converted into the respective oxide pillars by calcination. Various kinds of metal oxides such as $\mathrm{Al}_{2} \mathrm{O}_{3}, \mathrm{ZrO}_{2}, \mathrm{Fe}_{2} \mathrm{O}_{3}, \mathrm{Cr}_{2} \mathrm{O}_{3}$, and $\mathrm{TiO}_{2}$ have been introduced by this procedure. ${ }^{22)-27)}$ The pillar heights obtained so far are in the range of 0.7 to $1.0 \mathrm{~nm}$. Most of the pillared structured are thermally stable up to $600^{\circ} \mathrm{C}$, and keep the specific surface area as large as $300-500 \mathrm{~m}^{2} / \mathrm{g}$. The pillared clays generally show hydrophobic adsorption. This can be interpreted in terms of the loss of small exchangeable cations. $^{28)}$

Metal oxide sol particles can also be used as pillar precursors, as long as those are positively charged. The silica sol particles obtained by the hydrolysis of TEOS (tetraethoxysilane) are negatively charged, which can be converted into 

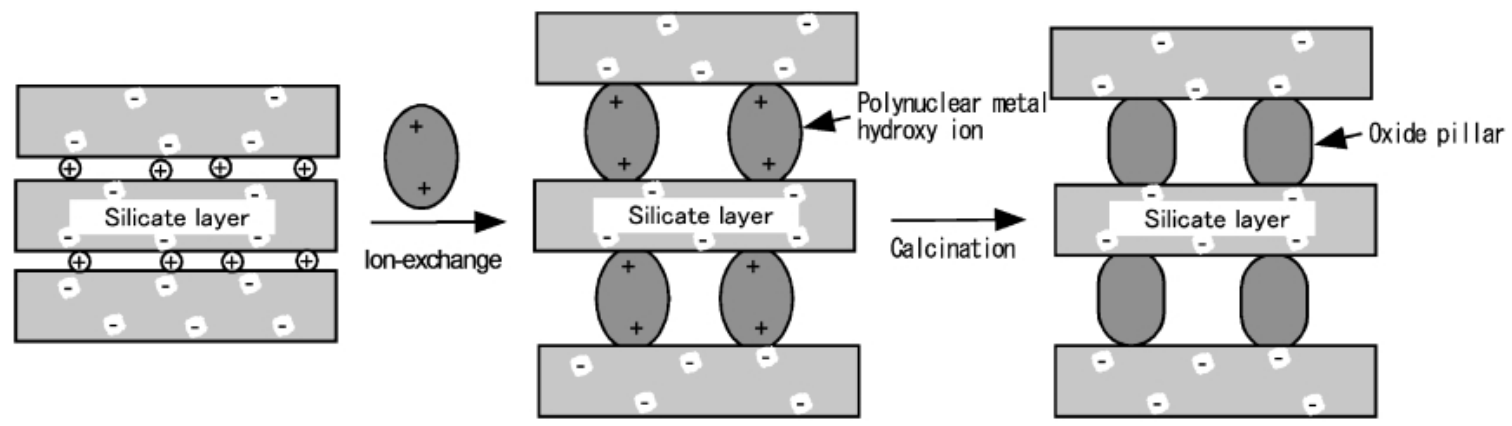

Fig. 2. Synthesis of pillared clays.

positively charged sols by the modification with small amount of titanium ions. ${ }^{29)}$ The modified sol particles can be ion exchanged with the interlayer cations of montmorillonite. The spacing increased rapidly soon after the clay was mixed with the sol solutions and then attained constant values at $\sim 4 \mathrm{~nm}$. The nitrogen adsorption isotherm of the sol pillared clay fits on the BET plot for the limited number of adsorption layers, suggesting that the pore sizes are much smaller than the pillar heights. The large basal spacing and a high surface area of about $400 \mathrm{~m}^{2} / \mathrm{g}$ were maintained at least up to $500^{\circ} \mathrm{C}$. The adsorption isotherms for large molecules such as xylenes and mesitylene fitted on the Langmuir linear plot, whereas those for smaller molecules such as water and methanol fitted rather on the BET plot. This finding also supports that the pore sizes are of the order of the molecular dimensions examined. Various mixed oxide sol particles were successfully used for pillaring such as $\mathrm{SiO}_{2}-\mathrm{Fe}_{2} \mathrm{O}_{3}$ and $\mathrm{SiO}_{2}-\mathrm{Cr}_{2} \mathrm{O}_{3} .{ }^{30), 31)}$

The discovery of pillared clays has established a new method to prepare inorganic microporous materials other than zeolites for the first time. However, the microporous materials so far developed are electric insulators. New types of micropores with semiconducting or metallic properties should also be developed for catalytic interest. A pillaring of semiconducting layered materials has been developed using a layer structured titanate, $\mathrm{Rb}_{x} \mathrm{Ti}_{1-x} \mathrm{Mn}_{x} \mathrm{O}_{2}$ with $\mathrm{SiO}_{2}$. The interlayer $\mathrm{Rb}$ cannot be directly ion-exchanged with metal hydroxyl cations such as those used in the formation of pillared clays. ${ }^{32), 33)}$ The Rb ions were first exchanged with alkylammonium ions, and TEOS was hydrolyzed between the layers to form silica pillar precursor, which was changed into $\mathrm{SiO}_{2}$ pillar between the layers by calcination. On calcination at $600^{\circ} \mathrm{C}$, silica pillared titanate with high specific surface area of about $800 \mathrm{~m}^{2} / \mathrm{g}$ and pores comparable with trimethylbenzene was obtained. The pillared titanate is so active as to oxidize $\mathrm{CO}$ even at temperatures as low as $60^{\circ} \mathrm{C} .{ }^{34)}$

\section{Anion exchangeable layer structured compounds}

As described above, anion-exchangeable layer structured crystals are very rare. Only hydrotalcite type layered double hydroxides (LDH) with a general formula of $\left[\mathrm{M}_{1-x}^{\mathrm{II}} \mathrm{M}_{x}^{\mathrm{III}}\right.$ $\left.(\mathrm{OH})_{2}\right]_{x} \mathrm{Y}_{x / z}^{z-} \cdot n \mathrm{H}_{2} \mathrm{O}$ are known. We have found that basic copper acetate of the botallackite type layer structure is a new type of anion-exchangeable crystals. ${ }^{35), 36)}$ Basic copper acetate was prepared by titrating a copper acetate solution with a $\mathrm{NaOH}$ solution up to $\mathrm{OH} / \mathrm{Cu}=1$. Green-colored platelet crystals with a composition of $\mathrm{Cu}_{2}(\mathrm{OH})_{3}\left(\mathrm{OCOCH}_{3}\right)$. $\mathrm{H}_{2} \mathrm{O}$ were obtained. The structures of the botallackite and $\mathrm{LDH}$ are very similar. Both structures can be derived from the $\mathrm{CdI}_{2}$ layer structure. In the $\mathrm{LDH}$ layer, the hydroxide

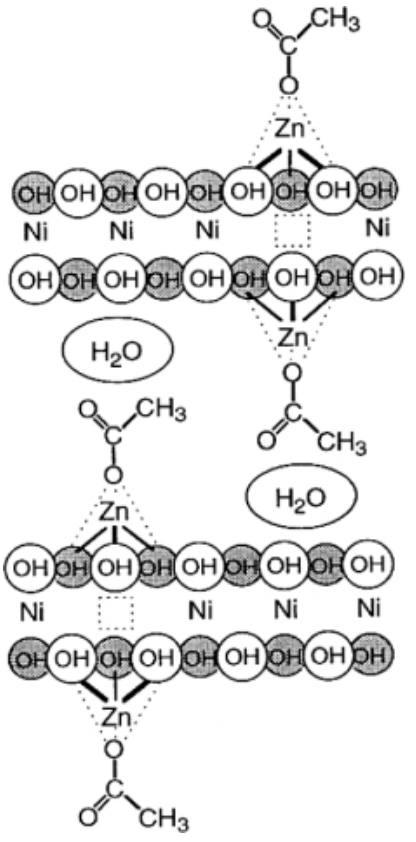

Fig. 3. Schematic structure of a new anion exchangeable layered crystal $\mathrm{Ni}_{1-x} \mathrm{Zr}_{2 x}(\mathrm{OH})_{2}\left(\mathrm{OCOCH}_{3}\right)_{2 x} \cdot n \mathrm{H}_{2} \mathrm{O}$.

layers are completed by hydroxy groups; the divalent metal ions are partially substituted with trivalent metal ions. The layers are positively charged. This excess charge is balanced by anions located between the layers. On the other hand, the botallackite has neutral hydroxy layers. A quarter of the hydroxy groups are substituted with acetate ions. Though the acetate framework ions are directly bound to $\mathrm{Cu}^{2+}$ ions, these are easily exchangeable with various anions.

The acetate ions of basic copper acetate are exchanged with various anions merely by dispersing in aqueous solutions of $\mathrm{NaX}\left(\mathrm{X}=\mathrm{Cl}, \mathrm{Br}, \mathrm{I}, \mathrm{NO}_{3}, \mathrm{ClO}_{4}\right)$, and $\mathrm{Na}_{2} \mathrm{SO}_{4}$ at room temperature. The competitive ion exchange reactions studied on several pairs of anions showed that the selectivity of the anions by the basic copper layers were in the following order; $\mathrm{Cl}^{-}>\mathrm{Br}^{-}>\mathrm{NO}_{3}{ }^{-}>\mathrm{CH}_{3} \mathrm{COO}^{-}, \mathrm{ClO}_{4}^{-}$. The alkanecarboxylate ion exchanged botallackites showed different types of magnetisms depending on the length of the alkyl chains. ${ }^{37)}$

Another new anion exchangeable layered compound with a composition of $\mathrm{Ni}_{1-x} \mathrm{Zr}_{2 x}(\mathrm{OH})_{2}\left(\mathrm{OCOCH}_{3}\right)_{2 x} \cdot n \mathrm{H}_{2} \mathrm{O}$ was prepared by hydrothermal hydrolysis of $\mathrm{Ni}-\mathrm{Zn}$ mixed acetate solutions. ${ }^{38)}$ The structure is related to zinc basic salt, $\mathrm{Zn}_{5}(\mathrm{OH})_{8} \mathrm{Cl}_{2} \cdot \mathrm{nH}_{2} \mathrm{O}$; as shown in Fig. 3, nickel ions form 
brucite-type hydroxide layers with vacancies, $\mathrm{Ni}_{1-x}(\mathrm{OH})_{2}$, and zinc ions occupy the tetrahedral sites above and below the vacant sites outside the hydroxide layers. Acetate ions are weakly bound to the $\mathrm{Zn}^{2+}$ ions, completing the tetrahedra, and easily exchanged with most of inorganic as well as organic anions. The reactions are reversible. It is interesting to note that exchange with $\left[\mathrm{Si}_{8} \mathrm{O}_{20}\right]^{8-}$ ions resulted in the formation of two-dimensional silicate layers analogous to those of $2: 1$ type clay minerals.

\section{Porous superconductors}

Recently, alkali and alkaline earth metals were doped into the interstices between close-packed fullerene balls, which were found to be superconductors with relatively high transition temperatures $\left(T_{\mathrm{c}}\right.$ 's $\left.) .{ }^{39)}, 40\right)$ These are not layer-structured compounds, but can be classified into a similar category of intercalation compounds. Layer-structured cuprate superconductors have intercalated structures from the beginning with superconducting $\mathrm{CuO}_{2}$ layers sandwiched by charge-controlling layers. ${ }^{41)}$ The richness of the type of layer-structured cuprates may reflect the flexible nature of layer-structured compounds with a degree of freedom along the direction perpendicular to the layers. It is interesting to note that the newly developed superconductor $\mathrm{MgB}_{2}$ with $T_{\mathrm{c}}=39 \mathrm{~K}$ is also a layer-structured compound. ${ }^{42}$ ) We have recently developed two different types of superconductors, which are also characterized as compounds with chemically modifiable interstices: barium containing silicon clathrate compound $\mathrm{Ba}_{8} \mathrm{Si}_{46}$ with $T_{\mathrm{c}}$ $\left.=8.0 \mathrm{~K},{ }^{43}\right)$ and a new family of layer-structured nitrides $\beta$ MNX $(\mathrm{M}=\mathrm{Zr}, \mathrm{Hf} ; \mathrm{X}=\mathrm{Cl}, \mathrm{Br}, \mathrm{I})$, which changed into superconductors by electron doping with alkali metal intercalation. ${ }^{44), 45)}$

\subsection{Silicon clathrate compounds}

The term clathrate is usually used to refer to a molecular compound in which small molecules or atoms of one species are trapped inside a cage-like structure formed by the other kind of molecules. Typical examples are gas hydrates such as $\mathrm{G}_{x}\left(\mathrm{H}_{2} \mathrm{O}\right)_{46}$ and $\mathrm{G}_{y}\left(\mathrm{H}_{2} \mathrm{O}\right)_{136}$, where the gas molecules $(\mathrm{G})$ such as $\mathrm{Ar}, \mathrm{CO}_{2}$, halogens and methane are trapped in the polyhedral cages formed by water molecules with hydrogen bonds. Silicon clathrate compounds are isotypic with the gas hydrates; the $\mathrm{O}-\mathrm{H} \cdots \mathrm{O}$ hydrogen bonds of the gas hydrates are replaced with $\mathrm{Si}-\mathrm{Si}$ covalent bonds, and the alkali metal atoms are trapped in the silicon polyhedra. Two types of silicon clathrate compounds are known, $\mathrm{M}_{x} \mathrm{Si}_{46}$ and $\mathrm{M}_{x} \mathrm{Si}_{136}(\mathrm{M}=\mathrm{Na}$, $\mathrm{K}, \mathrm{Rb}, \mathrm{Cs}$ ), which are composed of $\mathrm{Si}_{20}$ dodecahedra and $\mathrm{Si}_{24}$ tetrakaidecahedra, and $\mathrm{Si}_{20}$ dodecahedra and $\mathrm{Si}_{28}$ hexakaidecahedra, respectively. ${ }^{46)}$ The clathrate compounds are stable in air and even in acid solutions, except in hydrofluoric acid. Since the discovery of superconductivity in alkali-metaldoped fullerenes, much attention has been paid to silicon clathrate compounds. However, no superconductivity had been found. ${ }^{47)}$ Recently, we have succeeded in preparing barium containing silicon clathrate compounds isomorphous with the $\mathrm{Na}_{8} \mathrm{Si}_{46}$ structure. ${ }^{43)}$

Silicon clathrate compounds reported so far were prepared from alkali metal monosilicide MSi $(\mathrm{M}=\mathrm{Na}, \mathrm{K}, \mathrm{Rb}, \mathrm{Cs})$ by removing a part of the alkali metal by evacuation at elevated temperatures. The first barium-containing silicon clathrate compounds were also prepared from a ternary Zintl compound $\mathrm{Na}_{2} \mathrm{BaSi}_{4}$ by thermally removing a part of $\mathrm{Na} .{ }^{48)}$ The resulting compounds have a composition close to $\mathrm{Na}_{2} \mathrm{Ba}_{6} \mathrm{Si}_{46}$ in which $\mathrm{Na}$ atoms mainly occupy the $\mathrm{Si}_{20}$ dodecahedral cages and $\mathrm{Ba}$ atoms the $\mathrm{Si}_{24}$ tetrakaidecahedral cages (Fig. 4). It exhibited superconductivity at $T_{\mathrm{c}}$ of about $4 \mathrm{~K} .{ }^{49)}$ This is the

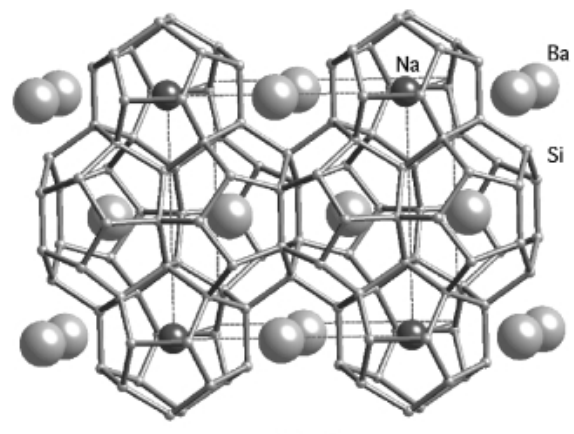

$\mathrm{Ba}_{6} \mathrm{Na}_{2} \mathrm{Si}_{46}$

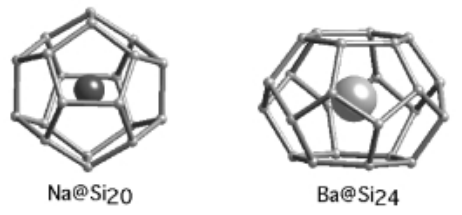

Fig. 4. Structure of the silicon clathrate compound $\mathrm{Ba}_{6} \mathrm{Na}_{2} \mathrm{Si}_{46}$ doped with $\mathrm{Na}$ and $\mathrm{Ba}$ atoms in the $\mathrm{Si}_{20}$ and $\mathrm{Si}_{24}$ cages, respectively.

first superconductor having Si-sp $p^{3}$ covalent networks. Bariumcontaining ternary silicon clathrate compounds, $\mathrm{Ba}_{8} \mathrm{Si}_{46-x} \mathrm{~T}_{x}$ $(\mathrm{T}=\mathrm{Ag}, \mathrm{Au}, \mathrm{Pt}, \mathrm{Ni}, \mathrm{Cu}, x \approx 6)$, had already been prepared by Cordier and $\mathrm{Woll}^{50)}$ in which the transition metals $\mathrm{T}$ substitute at some of the silicon sites in the network. These ternary compounds can be easily prepared by simply melting the constituents at elevated temperatures. We prepared the ternary compounds $\mathrm{Ba}_{8} \mathrm{Si}_{46-x} \mathrm{~T}_{x}(\mathrm{~T}=\mathrm{Ag}, \mathrm{Au}, \mathrm{Ni}, \mathrm{Cu} ; x \approx 6)$ in a similar way. However, those were found to be not superconductors down to $2 \mathrm{~K}$.

The binary silicon clathrate compound $\mathrm{Ba}_{8} \mathrm{Si}_{46}$ was prepared for the first time using high-pressure and high-temperature conditions of $3 \mathrm{GPa}$ at $800^{\circ} \mathrm{C} .{ }^{43)} \mathrm{Ba}_{8} \mathrm{Si}_{46}$ is isostructural with $\mathrm{Na}_{8} \mathrm{Si}_{46}$; all the metal sites are occupied by $\mathrm{Ba}$ atoms. It showed superconductivity at $T_{\mathrm{c}}=8.0 \mathrm{~K}$. We have also succeeded in the preparation of solid solutions of $\mathrm{Ba}_{8} \mathrm{~T}_{x} \mathrm{Si}_{46-x}(\mathrm{~T}=$ $\mathrm{Ag}, \mathrm{Au}, \mathrm{Ni}, \mathrm{Cu} ; 0 \leq x \leq 6)$ under high pressure conditions. The ternary compounds with $x \leq 3$ are superconductors and the $T_{\mathrm{c}}$ decreases with increasing $x .{ }^{51)}$ This finding suggests that the substitution of the Si sites in the network with transition metals is not favorable for the superconductivity.

Saito and Oshiyama, ${ }^{52)}$ and Moriguchi et al. ${ }^{53)}$ calculated the band structure of the Ba-containing silicon clathrate compounds using density-function analysis, and revealed that $\mathrm{Ba}$ states showed strong hybridization with $\mathrm{Si}_{46}$ states, giving a very high density of states at the Fermi level. Shimizu et al. ${ }^{54}$ ) measured the spin-lattice relaxation time $T_{1}$ for the three kinds of nuclei, ${ }^{29} \mathrm{Si},{ }^{137} \mathrm{Ba}$ and ${ }^{23} \mathrm{Na}$, of the barium-containing silicon clathrate by NMR. Three separate peaks were observed for ${ }^{29} \mathrm{Si}$. Metallic behavior was inferred from the temperature dependence of the $T_{1}$ measured for each peak. The Korringa relation $\left(T_{1} T=\right.$ const. $)$ held down to $4 \mathrm{~K} .{ }^{137} \mathrm{Ba}$ NMR also showed a similar behavior, suggesting that conduction electrons existed on $\mathrm{Si}$ and $\mathrm{Ba}$ atoms. The superconductivity of $\mathrm{Ba}_{8} \mathrm{Si}_{46}$ can be interpreted within the scope of the BCS phonon mediated mechanism, ${ }^{55)}$ and it is expected that if a hypothetical carbon clathrate is obtained, it will show a much higher $T_{\mathrm{c}}{ }^{56)}$

Recently we have prepared new types of clathrate compounds, $\mathrm{Ba}_{24} \mathrm{Si}_{100}$ and $\mathrm{Ba}_{24} \mathrm{Ge}_{100}$, in which barium-containing $\mathrm{Si}$ or $\mathrm{Ge}$ dodecahedra $\left(\mathrm{Ba} @ \mathrm{Si}_{20}\right.$ or $\left.\mathrm{Ba} @ \mathrm{Ge}_{20}\right)$ are linked 
by face sharing to form a zeolite-like three dimensional network. ${ }^{57), 58)}$ Superconductivity of $\mathrm{Ba}_{24} \mathrm{Ge}_{100}$ was obtained below $0.24 \mathrm{~K}$ at ambient pressure. ${ }^{59)} \mathrm{A}$ silicon clathrate compound doped with the electronegative element iodine, $\mathrm{I}_{8} \mathrm{Si}_{46-x} \mathrm{I}_{x}(x=1.5 \pm 0.5)$, has been prepared. This is not a superconductor, but a semiconductor. ${ }^{60)}$

7.2 Layer structured nitride superconductors

There are two types of polymorphs in the ternary layerstructured nitrides $\mathrm{MNX}(\mathrm{M}=\mathrm{Zr}, \mathrm{Hf} ; \mathrm{X}=\mathrm{Cl}, \mathrm{Br}, \mathrm{I})$; the $\alpha$-form with the $\mathrm{FeOCl}$ structure and the $\beta$-form with the SmSI structure. ${ }^{61)}$ The $\beta$ - $\mathrm{MNCl}$ consists of double $\mathrm{MN}$ layers with a sequence of $\mathrm{M}-\mathrm{N}-\mathrm{N}-\mathrm{M}$ sandwiched by close-packed chlorine layers, the $\mathrm{Cl}-\mathrm{M}-\mathrm{N}-\mathrm{N}-\mathrm{M}-\mathrm{Cl}$ slabs being stacked rhombohedrally. The crystals are semiconductors with a band gap of about 3-4 eV.

$\beta$ - ZrNCl was first prepared by Juza and Henners by the ammonolysis of $\mathrm{ZrCl}_{4}$ at elevated temperatures. ${ }^{62)}$ We have developed a new simple route, where $\mathrm{Zr}$ metal or $\mathrm{ZrH}_{2}$ powders were reacted with $\mathrm{NH}_{4} \mathrm{Cl}$ at $650^{\circ} \mathrm{C} .{ }^{63)}$

$$
\mathrm{Zr}\left(\text { or } \mathrm{ZrH}_{2}\right)+\mathrm{NH}_{4} \mathrm{Cl} \longrightarrow \beta-\mathrm{ZrNCl}+2(\text { or } 3) \mathrm{H}_{2}
$$

The as-prepared $\beta$ - $\mathrm{ZrNCl}$ could be further purified by a chemical transport with the aid of $\mathrm{NH}_{4} \mathrm{Cl}^{64)}$ According to a similar procedure using metal powders and ammonium halides $\mathrm{NH}_{4} \mathrm{X}$ $(\mathrm{X}=\mathrm{Cl}, \mathrm{Br}, \mathrm{I})$, all kinds of $\mathrm{MNX}(\mathrm{M}=\mathrm{Zr}, \mathrm{Hf} ; \mathrm{X}=\mathrm{Cl}, \mathrm{Br}, \mathrm{I})$ can be prepared. The $\beta$-forms of $\mathrm{ZrNI}, \mathrm{HfNBr}$ and HfNI were prepared under high pressure conditions. ${ }^{65)}$ Single crystals of $\beta$-MNX were grown using $\mathrm{NH}_{4} \mathrm{X}$ as fluxes under high pressure, and the crystal structures were determined by the single crystal X-ray analysis. ${ }^{66), 67)}$

On intercalation of lithium by the reaction with a $n$-butyllithium $(n-\mathrm{BuLi})$ solution in hexane, $\beta-\mathrm{ZrNCl}$ is changed into a superconductor with a $T_{\mathrm{c}}$ of about $13 \mathrm{~K} .{ }^{44)} \beta-\mathrm{HfNCl}$ is isostructural with $\beta$ - $\mathrm{ZrNCl}$. The reactivity of $\beta$ - $\mathrm{HfNCl}$ with $n$-BuLi is not high enough for the lithium intercalation, ${ }^{68), 69)}$ but it reacts with a $\mathrm{Li}$ naphthalene (Naph-Li) solution in tetrahydrofuran (THF) to form the Li and THF co-intercalated compound $\mathrm{Li}_{0.48}(\mathrm{THF})_{y} \mathrm{HfNCl}$ as shown in Fig. 5, which shows superconductivity of $T_{\mathrm{c}}=25.5 \mathrm{~K} .{ }^{45)}$

It is well known that a series of transition metal nitrides with the rock salt structure become superconductors, such as TiN, $\mathrm{ZrN}, \mathrm{HfN}$, and $\mathrm{NbN}$ with $T_{\mathrm{c}}$ 's at $5.5,10.7,8.8$, and $18.0 \mathrm{~K}$, respectively. The structure of $\beta-\mathrm{ZrNCl}$ can be seen as being composed of $\mathrm{ZrN}$ double layers sliced from a $\mathrm{ZrN}$ crystal of the $\mathrm{NaCl}$ structure and sandwiched by chloride layers. Since the $T_{\mathrm{c}}$ of $\mathrm{HfN}(8.8 \mathrm{~K})$ is lower than that of $\mathrm{ZrN}(10.7 \mathrm{~K})$, it was expected that $\beta$ - $\mathrm{HfNCl}$ might have a lower $T_{\mathrm{c}}$ than that of $\beta$ - $\mathrm{ZrNCl}$ even if it might become a superconductor upon lithium intercalation. It is surprising that the $T_{\mathrm{c}}$ of $\mathrm{Li}_{0.48}$ $(\mathrm{THF})_{y} \mathrm{HfNCl}$ is much higher than that of the zirconium analog. It should be noted that the lattice dimensions of $\mathrm{HfNCl}$ are very close to those of $\mathrm{ZrNCl}$. The bond lengths of $\mathrm{M}-\mathrm{N}(0.219-0.211 \mathrm{~nm})$ of $\beta$ - $\mathrm{MNCl}(\mathrm{M}=\mathrm{Zr}, \mathrm{Hf})$ are shorter than those of the corresponding nitrides $(0.229-0.226 \mathrm{~nm})$ of the $\mathrm{NaCl}$ structure, and the honeycomb networks of $\mathrm{ZrN}$ and HfN between the chlorine layers are almost coplanar with the bond angle $\mathrm{N}-\mathrm{M}-\mathrm{N}$ of $115.6^{\circ}$. The stronger bonding in the $\mathrm{M}-\mathrm{N}$ network and the coplanarity may be the reason for the higher $T_{\mathrm{c}}$ of the layered phases compared with the $\mathrm{NaCl}$ phases.

We can change the amount of doping and the kinds of doped metals as well as the separation of the superconducting layers by co-intercalation of solvent molecules with metals. ${ }^{70)}$ The amount of lithium uptake by $\beta$ - $\mathrm{HfNCl}$ can be controlled

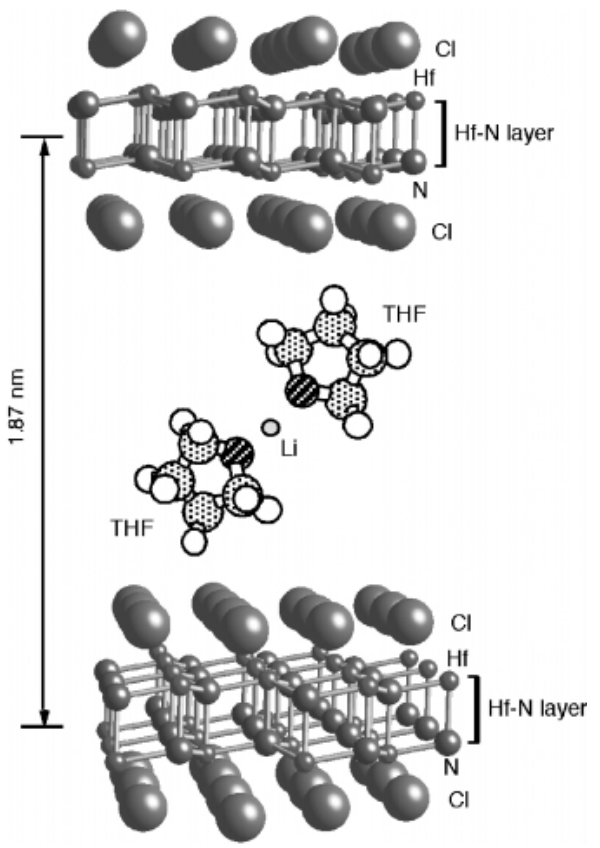

Fig. 5. Schematic illustration of $\beta-\mathrm{HfNCl}$ co-intercalated with $\mathrm{Li}$ and THF molecules.

by changing the amount of Naph-Li used. The $T_{\mathrm{c}}$ determined by the magnetic susceptibility measurements gradually decreased from 25.5 to $24.4 \mathrm{~K}$ with the increase of the amount of lithium intercalation from $x=0.13$ to 0.97 in $\mathrm{Li}_{x}(\mathrm{THF})_{y}$ $\mathrm{HfNCl}$. Similar decreases of $T_{\mathrm{c}}$ by the overdoping of alkali metals were also observed for the intercalated series of $\beta$ $\mathrm{ZrNCl}$ with alkali metals. ${ }^{70)}$ The decrease of $T_{\mathrm{c}}$ can be explained in terms of the increase of the screening of the phonon-electron interaction, which may decrease the average electron pairing interaction for the formation of Cooper pairs. It would be reasonable to expect an enhanced anisotropic effect in the superconductivity of the co-intercalated system. $\mathrm{Na}$ intercalated $\beta$ - $\mathrm{HfNCl}$ was prepared using a $\mathrm{Na}$ naphthalene (Naph-Na) solution in THF. In this reaction, THF did not co-intercalate with $\mathrm{Na}$, and only Na-intercalated compounds were obtained. This is due to the smaller polarizing power of $\mathrm{Na}$ ions. However, propylene carbonate (PC) with a much larger dipole moment than that of THF could be postcointercalated with $\mathrm{Na}$, expanding the spacing up to $22 \AA$. The co-intercalation effect on the superconductivity was investigated by keeping the amount of $\mathrm{Na}$ at the same level before and after the co-intercalation. The $T_{\mathrm{c}}$ was slightly shifted toward a higher temperature by about $2 \mathrm{~K}$ upon co-intercalation of PC molecules. ${ }^{71)}$ A significant influence of the co-intercalation on the superconducting property was found in the magnetization reversible temperature observed between the ZFC (zero-field cooling) and FC (field cooling) magnetization curves. The reversible range significantly increased by the co-intercalation, indicating that the magnetic flux was only weakly pinned in the co-intercalation compound.

A new electron-doping method has been developed by a partial deintercalation of chlorine layers from $\beta$ - $\mathrm{ZrNCl}$ and $\beta$ - $\mathrm{HfNCl}$ using alkali metal azides $\left.\mathrm{RN}_{3}(\mathrm{R}=\mathrm{Na}, \mathrm{K}, \mathrm{Rb}) ;^{72}\right)$

$$
\beta-\mathrm{MNCl}+x \mathrm{RN}_{3} \longrightarrow \beta-\mathrm{MNCl}_{1-x}+x \mathrm{RCl}+3 x / 2 \mathrm{~N}_{2}
$$

The deintercalated crystals were much stable in air, and 
showed superconductivity with similar $T_{\mathrm{c}}$ 's to those of alkali metal intercalated crystals.

Uemura et al. ${ }^{73)}$ measured the muon spin relaxation rate of $\mathrm{Li}_{0.48}(\mathrm{THF})_{y} \mathrm{HfNCl}$, and estimated the two-dimensional (2D) Fermi temperature $T_{\mathrm{F}}$. The plot of $T_{\mathrm{c}}$ versus $T_{\mathrm{F}}$ lies on the line connecting the points of typical exotic superconductors such as high- $T_{\mathrm{c}}$ cuprates and organic superconductors of the (BEDT-TTF $)_{2}-\mathrm{X}$ system. Magnetic susceptibility and NMR studies have been performed on the $\mathrm{Li}_{0.48}(\mathrm{THF})_{y} \mathrm{HfNCl}$ sample compressed into a pellet with the $\mathrm{c}$ axis aligned perpendicular to the plane of the pellet. ${ }^{74), 75)}$ The measurements showed that the compound has quasi-2D electronic properties. The phase diagram of the upper critical field $\left(H_{\mathrm{c} 2}\right)$ versus temperature was found to be anisotropic. The $H_{\mathrm{c} 2}$ 's were determined to be 348 and $93 \mathrm{kOe}$ in the $a b$ plane and along the $c$ axis, respectively. The coherence length $(\xi)$ was estimated to be 59.6 and $15.9 \AA$ for the in-plane direction and that perpendicular to the layer, respectively. The finding that $\xi$ in the $c$ direction is shorter than the interlayer distance of $d=18.7 \AA$ implies that the superconductivity is coupled by Josephson tunneling between the adjacent layers. The magnetic susceptibility and NMR measurements revealed the following unconventional aspects of the superconductivity of $\mathrm{Li}_{0.48}(\mathrm{THF})_{y}$ $\mathrm{HfNCl}$ : (a) the electronic density of states at the Fermi level is small, $N^{*}\left(E_{\mathrm{F}}\right) \sim 0.25$ states/(eV spin f.u.), (b) mass enhancement is negligible, $m^{*} / m_{0} \sim 1$, (c) electron-phonon coupling is weak, $\lambda_{\text {ep }} \ll 1$, (d) the electronic correlation effect is weak, and (e) the electronic density parameter is large, $r_{\mathrm{s}}^{2 \mathrm{D}} \sim 10.3$ (i.e., low carrier density). Considering these findings together, Tou et al. ${ }^{74)}$ proposed the possibility of a chargefluctuation mechanism for the superconductivity.

\section{Conclusions}

Materials contain various types of interstices. As described with some examples, the interstices have three characteristic functions, (i) recognition (atoms, ions, molecules, and functional groups can be recognized), (ii) storage (atoms, molecules and energies are stored), and (iii) transport (electrons, holes, ions, and molecules, vibrations are transferred). New functional materials with interesting properties will be created by combination of these functions.

Acknowledgments The author started the study of intercalation as a graduate student of Osaka University under a supervision of Profs. Mitsue Koizumi and Fumikazu Kanamaru. He wishes to express sincere thanks to all of the colleagues and students for their continuous collaboration, discussion, and encouragements to achieve these studies.

\section{References}

1) Yamanaka, S. and Kanamaru, F., Kagaku-Sosetsu, No. 40, pp. 65-81, Chem. Soc. Jpn. (1983) [in Japanese].

2) Yamanaka, S., Kanamaru, F. and Koizumi, M., J. Phys. Chem., Vol. 78, pp. 42-44 (1974).

3) Yamanaka, S., Kanamaru, F. and Koizumi, M., J. Phys. Chem., Vol. 79, 1285-1288 (1975).

4) Norrish, K. and Quirk, J. P., Nature (London), Vol. 173, 255-256 (1954).

5) Onikata, M., Kondo, M., Hayashi, N. and Yamanaka, S., Clays Clay Miner., Vol. 47, pp. 672-677 (1999).

6) Onikata, M., Kondo, M. and Yamanaka, S., Clays Clay Miner., Vol. 47, pp. 678-681 (1999).

7) Yamanaka, S. and Hattori, M., "Inorganic Phosphate Materials,” Kanazawa, T., Ed., Kodansha/Elsevier (1989) Chap. 6.

8) Yamanaka, S. and Tanaka, M., J. Inorg. Nucl. Chem., Vol. 41, pp. 45-48 (1979).
9) Clayden, N. J., J. Chem. Soc. Dalton Trans., Vol. 8, pp. 1877-1881 (1987).

10) Yamanaka, S., Inorg. Chem., Vol. 15, pp. 2811-2817 (1976).

11) Nakano, H., Ohno, T. and Yamanaka, S., Chem. Lett., pp. 9-12 (1994).

12) Yamanaka, S., "Soft Chemictry Routes to New Materials," Rouxel, J., Tournoux, M. and Brec, R., Trans Tech Publications (1994) pp. 69-80.

13) Yamanaka, S., Maeda, H. and Tanaka, M., J. Inorg. Nucl. Chem., Vol. 41, pp. 1187-1191 (1979).

14) Yamanaka, S. and Hattori, M., Chem. Lett., pp. 1073-1076 (1979).

15) Yamanaka, S., Matsunaga, M. and Hattori, M., J. Inorg. Nucl. Chem., Vol. 43, pp. 1343-1346 (1981).

16) Yamanaka, S. and Hattori, M., Inorg. Chem., Vol. 20, pp. 1929-1931 (1981).

17) Yamanaka, S., Sakamoto, K. and Hattori, M., J. Phys. Chem., Vol. 85, pp. 1930-1933 (1981).

18) Yamanaka, S., Sakamoto, K. and Hattori, M., J. Phys. Chem., Vol. 88, pp. 2067-2070 (1984).

19) Yamanaka, S., "Properties and Applications of Porous Materials," Takeuchi, Y., Eds., Fuji Techno System (1999) pp. 111-121 [in Japanese].

20) Yamanaka, S. and Hattori, M., "Chemistry of Microporous Crystals," Inui, T., Namba, S. and Tatsumi, T., Eds., Kodansha, Tokyo (1991) pp. 89-96.

21) Yamanaka, S. and Brindley, G. W., Clays Clay Miner., Vol. 27, pp. 119-124 (1979).

22) Brindley, G. W. and Yamanaka, S., Amer. Miner., Vol. 64, pp. 830-835 (1979).

23) Yamanaka, S., Doi, T., Sako, S. and Hattori, M., Mat. Res. Bull., Vol. 19, pp. 161-168 (1984).

24) Yamanaka, S., Nishihara, T., Hattori, M. and Suzuki, Y., Mat. Chem. Phys., Vol. 17, pp. 87-101 (1987).

25) Yamanaka, S. and Makita, K., J. Porous Materials., Vol. 1, pp. 29-41 (1995).

26) Yamanaka, S. and Hattori, M., Catal. Today, Vol. 2, pp. 261-270 (1988).

27) Yamanaka, S., Am. Ceram. Soc. Bull., Vol. 70, pp. 1056-1058 (1991).

28) Yamanaka, S., Malla, P. B. and Komarneni, S., J. Colloid Interface Sci., Vol. 134, pp. 51-58 (1990).

29) Yamanaka, S., Inoue, Y., Hattori, M., Okumura, F. and Yoshikawa, M., Bull. Chem. Soc. Jpn., Vol. 65, pp. 2494-2500 (1992).

30) Han, Y.-S., Matsumoto, H. and Yamanaka, S., Chem. Mater., Vol. 9, pp. 2013-2018 (1997).

31) Han, Y.-S. and Yamanaka, S., J. Porous Mat., Vol. 5, pp. 111-119 (1998).

32) Yamanaka, S., Kunii, K. and Xu, Z.-L., Chem. Mater., Vol. 10, pp. 1931-1936 (1998).

33) Xu, Z.-L. and Yamanaka, S., J. Porous Mater., Vol. 8, pp. 91-97 (2001).

34) Xu, Z.-L., Inumaru, K. and Yamanaka, S., Appl. Catalysis A, Vol. 210, 217-224 (2001).

35) Yamanaka, S., Sako, T. and Hattori, M., Chem. Lett., pp. 1869-1872 (1989).

36) Yamanaka, S., Sako, T., Seki, K. and Hattori, M., Solid State Ionics, Vol. 53-56, pp. 527-533 (1992).

37) Fujita, W. and Awaga, K., Inorg. Chem., Vol. 35, pp. 1915-1917 (1996).

38) Yamanaka, S., Ando, K. and Ohashi, M., Mat. Res. Soc. Symp. Proc., Vol. 371, pp. 131-142 (1995).

39) Fleming, R. M., Rosseinsky, M. J., Ramirez, A. P., Murphy, D. W., Tully, J. C., Huddon, R. C., Siegrist, T., Tycko, R., Glarum, S. H., Marsh, P., Dabbagh, G., Zahurak, S. M., Makhija, A. V. and Hampton, C., Nature (London), Vol. 352, pp. 701-703 (1991).

40) Yildirim, T., "Advances in The Chemistry and Physics of Fullerenes and Related Materials," Ed. Kadish, K. M., Electrochem. Soc., Pennington (1998) Vol. 6, pp. 360-383. 
41) Cava, R. J., Science, Vol. 247, pp. 656-662 (1990).

42) Nagamatsu, J., Nakagawa, N., Muranaka, T., Zenitani, Y. and Akimitsu, J., Nature (London), Vol. 410, pp. 63-64 (2001).

43) Yamanaka, S., Enishi, E., Yasukawa, T. and Fukuoka, H., Inorg. Chem., Vol. 39, pp. 56-58 (2000).

44) Yamanaka, S., Kawaji, H., Hotehama, K. and Ohashi, M., Adv. Mat., Vol. 8, pp. 771-774 (1996).

45) Yamanaka, S., Hotehama, K. and Kawaji, H., Nature (London), Vol. 392, pp. 580-582 (1998).

46) Kasper, J. S., Hagenmuller, P., Pouchard, M. and Cros, C., Science, Vol. 150, pp. 1713-1714 (1965).

47) Roy, S. B., Sim, E. and Caplin, A. D., Philos. Mag. B, Vol. 65, pp. 1445-1450 (1992).

48) Yamanaka, S., Horie, H., Nakano, H. and Ishikawa, M., Fullerene Sci.Tech., Vol. 3, pp. 21-28 (1995).

49) Kawaji, H., Horie, H., Yamanaka, S. and Ishikawa, M., Phys. Rev. Lett., Vol. 74, pp. 1427-1429 (1995).

50) Cordier, G. and Woll, P., J. Less-Common Metals, Vol. 169, pp. 291-302 (1991).

51) Nozue, Y., Hosaka, G., Enishi, E. and Yamanaka, S., Molecular Crystals and Liquid Crystals, Vol. 341, pp. 509-514 (2000).

52) Saito, S. and Oshiyama, A., Phys. Rev. B, Vol. 51, pp. 2628-2631 (1995).

53) Moriguchi, K., Yonemura, M., Munetoh, S., Shibagaki, S., Shintani, A. and Yamanaka, S., Phys. Rev. B, Vol. 61, pp. 9859-9862 (2000).

54) Shimizu, F., Maniwa, Y., Kume, K., Kawaji, H., Yamanaka, S. and Ishikawa, M., Phys. Rev. B, Vol. 54, pp. 13242-13246 (1996).

55) Tanigaki, K., Shimizu, T., Itoh, K. M., Teraoka, J., Morimoto, Y. and Yamanaka, S., Nature Materials, Vol. 2, pp. 653-655 (2003).

56) Connétable, D., Timoshevskii, V., Masenelli, B., Beille, J., Marcus, J., Barbara, B., Saitta, A. M., Riganane, G.-M., Melinon, P., Yamanaka, S. and Blasé, X., Phys. Rev. Lett., Vol. 91, pp. 247001/1-4 (2003).

57) Fukuoka, H., Ueno, K. and Yamanaka, S., J. Organometal., Vol. 611, pp. 543-546 (2000).

58) Fukuoka, F., Yamanaka, S., Abe, H., Yoza, K. and Haming,
L., J. Solid State Chem., Vol. 151, pp. 117-121 (2000).

59) Grosche, F. M., Yuan, H. Q., Carrillo-Cabrera, W., Paschen, S., Langhammer, C., Kromer, F., Sparn, G., Baenitz, M., Grin, Yu. and Steglich, F., Phys. Rev. Lett., Vol. 87, pp. 247003/1-4 (2001).

60) Reny, E., Yamanaka, S., Cros, C. and Pouchard, M., Chem. Commun., pp. 2505-2506 (2000).

61) Yamanaka, S., Annual Rev. Mater. Sci., Vol. 30, pp. 53-82 (2000).

62) Juza, R. and Heners, J., Z. Anorg. Allg. Chem., Vol. 332, pp. 159-172 (1964).

63) Ohashi, M., Yamanaka, S., Sumihara, M. and Hattori, M., J. Solid State Chem., Vol. 75, pp. 99-104 (1988).

64) Ohashi, M., Yamanaka, S. and Hattori, M., J. Solid State Chem., Vol. 77, pp. 342-347 (1988).

65) Yamanaka, S., Itoh, K., Fukuoka, H. and Yasukawa, M., Inorg. Chem., Vol. 39, pp. 806-809 (2000).

66) Chen, X., Koiwasaki, T. and Yamanaka, S., J. Solid State Chem., Vol. 159, pp. 80-86 (2001).

67) Chen, X., Fukuoka, H. and Yamanaka, S., J. Solid State Chem., Vol. 163, pp. 77-83 (2002).

68) Ohashi, M., Shigeta, T., Yamanaka, S. and Hattori, M., J. Electrochem. Soc., Vol. 136, pp. 1086-1089 (1989).

69) Ohashi, M., Uyeoka, K., Yamanaka, S. and Hattori, M., Bull. Chem. Soc. Jpn., Vol. 64, pp. 2814-2818 (1991).

70) Kawaji, H., Hotehama, K. and Yamanaka, S., Chem. Mater., Vol. 9, pp. 2127-2130 (1997).

71) Yamanaka, S., Hotehama, K., Koiwasaki, T., Kawaji, H., Fukuoka, H., Shamoto, S. and Kajitani, T., Physica C, Vol. 341-348, pp. 692-702 (2000).

72) Zhu, L. and Yamanaka, S., Chem. Mater., Vol. 15, pp. 1897-1902 (2003).

73) Uemura, Y. J., Fudamoto, Y., Gat, I. M., Larkin, M. I., Luke, G. M., Merrin, J., Kojima, K. M., Itoh, K., Yamanaka, S., Heffner, R. H. and MacLaughlin, D. E., Physica B, Vol. 289-290, pp. 389-392 (2000)..

74) Tou, H., Maniwa, Y., Koiwasaki, T. and Yamanaka, S., Phys. Rev. Lett., Vol. 86, pp. 5775-5778 (2001).

75) Tou, H., Omata, D., Maniwa, Y., Itoh, K. and Yamanaka, S., Physica C, Vol. 341-348, pp. 2139-2140 (2000).

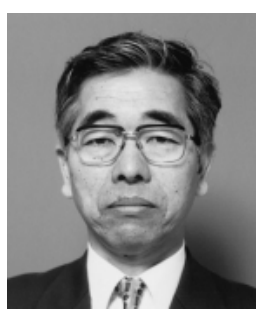

Shoji Yamanaka is a professor of Department of Applied Chemistry, Graduate School of Engineering, Hiroshima University. He received his Master and Doctor degrees of Science from Osaka University in 1971 and 1975, respectively. He joined Osaka Prefecture University as a research associate in 1972 . He moved to Hiroshima University as an associate professor in 1978, and was promoted to professor in 1991. His research field is inorganic materials chemistry; current research interests are layer structured and intercalation compounds, porous materials, and high pressure synthesis. 